\title{
Group based interventions for mothers and mothers plus children reduced mental health problems in adolescent children of divorced parents
}

\author{
Wolchik SA, Sandler IN, Millsap RE, et al. Six-year follow-up of preventive interventions for children of divorce: a \\ randomized controlled trial. JAMA 2002;288:1874-81.

\section{QUESTION: Do group based interventions for mothers and mothers plus children reduce mental health problems in adolescent children of divorced parents?}

\begin{abstract}
Design
Randomised \{allocation concealed\}*, blinded \{data collectors $\}^{*}$, controlled trial with 6 years of follow up.

\section{Setting}

A metropolitan area of Phoenix, Arizona, USA.

\section{Patients}

240 families with children 9-12 years of age (mean age 11 y, 51\% boys) of divorced parents. Families were included if the mother was the primary residential parent; neither the mother nor any child was receiving treatment for mental health problems; mother had not remarried, did not plan to remarry, and had no live in boyfriend; custody was stable; mother and child were

fluent in English; child was not learning disabled; and
\end{abstract}

Source of funding: National Institute of Mental Health. For correspondence:

Arizona State

University, Tempe, AZ,

USA.

\section{COMMENTARY}

Parental divorce negatively affects child behaviour, school and social performance, use of drugs, and emotional health, ${ }^{1}$ and is associated with an increased risk of attempted suicide. ${ }^{2}$ In 1995, approximately $40 \%$ of children in the US had experienced parental divorce before their $16^{\text {th }}$ birthday. ${ }^{3}$ UK rates are somewhat lower at approximately $28 \%{ }^{4}$ Effective interventions are needed to help children and parents cope with the stresses of divorce.

Wolchik et al found that group based interventions aimed at mothers only or mothers plus children reduced mental health problems in adolescents. The benefits were strongest in adolescents with higher baseline levels of mental health problems. However, the generalisability of the findings may be limited because the sample comprised a homogeneous group of mainly white, middle class mothers of healthy children.

Future research could assess the role of a child's relationship with the non-custodial parent as a source of support or stress. ${ }^{1}$ As well, replication of the study with parents (including fathers) and children of various ethnic, socioeconomic, and mental health backgrounds is needed. Information is also needed on the cost effectiveness of the MP and MPCP. Each programme will require substantial resources in terms of staff (master's degree level clinicians), staff training, and other administrative requirements. Given that the MP and MPCP programmes did not differ for any of the outcomes, the MP may be a more feasible and less costly alternative. Until such information becomes available, nurses in public health and family practice settings can still monitor children of families who are going through the divorce process, particularly those with existing mental health problems, and refer them to appropriate existing services.

Loretta Secco, RN, PhD Professor, Faculty of Nursing University of Manitoba Winnipeg, Manitoba, Canada

1 Videon TM. The effects of parent-adolescent relationships and parental separation on adolescent well-being. Journal of Marriage and the Family 2002;64:489-503.

2 Dube SR, Anda RF, Felitti VJ, et al. Childhood abuse, household dysfunction, and the risk of attempted suicide throughout the life span: findings from the Adverse Childhood Experiences Study. JAMA 2001:286:3089-96.

3 Tanner JL. Parental separation and divorce: can we provide an ounce of prevention? Pediatrics 2002;110:1007-9.

4 McMunn AM, Nazroo JY, Marmot MG et al. Children's emotional and behavioural well-being and the family environment: findings from the Health Survey for England. Soc Sci Med 2001;53:423-40. children with attention deficit/hyperactivity disorder were taking medication. Families were excluded if the child scored $>17$ on the Children's Depression Inventory, endorsed an item about suicidal ideation, or scored $>97^{\text {th }}$ percentile on the Externalizing Subscale of the Child Behavior Checklist. 218 families (91\%) were included in the 6 year follow up analysis (mean age of adolescents $17 \mathrm{y}$ ).

\section{Intervention}

81 families were allocated to the mother programme (MP), which comprised 11 group sessions (1.75 $\mathrm{h}$ /session) that focused on improving the quality of the mother-child relationship, effective discipline, increasing fathers' access to children, and reducing interparental conflict. In addition, 2 structured individual sessions were given to tailor programme activities to individual needs. 83 families were allocated to the mother plus child programme (MPCP), which included the MP plus 11 sessions for children. These also focused on effective coping and reducing negative thoughts about divorce stressors. 76 families were allocated to the control group and received books on adjustment after divorce.

\section{Main outcome measures}

Diagnosis of a mental disorder, alcohol and drug abuse, externalising and internalising problems, and number of sexual partners.

\section{Main results}

Analysis was by intention to treat. The MP and control groups did not differ for mental disorders ( $18 \% v 24 \%$, $\left.\{\mathrm{p}=0.14\}^{*}\right)$ or drug abuse or dependence $(5.3 \%$ v $2.9 \%$, $\{\mathrm{p}=0.81\}$ *). However, adolescents in the MP group had less alcohol $(\mathrm{p}=0.005)$, marijuana $(\mathrm{p}=0.02)$, and other drug use $(\mathrm{p}=0.01)$ than those in the control group. Adolescents in the MPCP group had a lower rate of mental disorders ( $11 \%$ v 24\%; adjusted odds ratio 4.50 , $95 \%$ CI 1.53 to 13.70$)$ and fewer sexual partners $(0.68 \mathrm{v}$ $1.65, \mathrm{p}=0.01)$ than adolescents in the control group. The MPCP and control groups did not differ for marijuana, alcohol, or other drug abuse. The MP and MPCP groups did not differ for any of the outcomes.

\section{Conclusion}

In children of divorced parents, group based interventions for mothers and mothers plus children were more effective than usual care for reducing mental health problems in mid to late adolescence.

*Information provided by author. 